\title{
2018 ABME Paper Awards
}

Each year, the top papers in Annals of Biomedical Engineering (ABME) are selected for editorial awards that are presented at the Biomedical Engineering Society (BMES) Annual Meeting. At the 2018 BMES Annual Meeting, a total of six awards were presented: one paper with the most citations, ${ }^{6}$ one paper with the most downloads, ${ }^{1}$ and four papers that received editor's choice awards. ${ }^{2-5}$ These papers were selected from a total of 249 papers published in 2017. Three of the six awarded authors were able to attend BMES to receive their award in person (Fig. 1). While the citation and download awards were selected purely quantitatively, the editor's choice awards were selected by the journal's editorial board. Each deputy editor-in-chief chose finalists based on the impact and quality of the papers, while also considering the number and rate of citations and downloads the papers received. The editor-in-chief selected the four papers to be awarded from those finalists. The awards covered a wide range of topics, including biomaterials, tissue engineering, and biomechanics.

Zhang et al. ${ }^{6}$ provided a thorough review of $3 \mathrm{D}$ bioprinting for tissue engineering purposes. They described recent advances in the technology as well as applications including fabrication of tissues and organs. They also presented different challenges associated with $3 \mathrm{D}$ bioprinting and ways to address those challenges for future progress. At the time of awards selection, the paper had 41 citations.

Campolettano et al. ${ }^{1}$ performed the first study evaluating head and neck injury risks associated with drone impacts. They tested a range of drone sizes in both live flight and drop-style head impacts to a Hybrid III test dummy. The results showed that some larger commercially available drone models are not safe to operate over people. The methods and results presented in this study could be used to inform future drone safety standards. The paper had over 3800 downloads at the time of awards selection.

Zadpoor and Malda provided context for and summarized the contents of the ABME special issue on additive manufacturing applied to biomaterials and tissue engineering. Additive manufacturing not only expedites the process of biofabrication, but can also provide patient-specific devices and services. The applications of additive manufacturing to healthcare are recent, but rapidly growing, and show great promise for the future.

Chatzistergos et $\mathrm{al}^{2}$ evaluated the effect of varying footwear material stiffness on plantar pressure. They used both in vivo and mechanical tests to determine optimum stiffnesses for reducing plantar pressure. The optimum stiffness increased with increasing body mass and body mass index. These data could be used as the basis for selecting therapeutic footwear and orthotic materials in a clinical setting.

Müller et $a l .{ }^{4}$ developed a bioink to be used for cartilage bioprinting. They combined alginate sulfate, a hydrogel system that supports the chondrocyte phenotype but is not printable, with nanocellulose for a printable bioink. The alginate sulfate-nanocellulose combination had high shape fidelity to create complex 3D structures, but the cell viability and growth on the printed material was highly dependent on the printing conditions.

Duan $^{3}$ reviewed 3D bioprinting techniques and bioinks, and then summarized recent advances in the technology applied to cardiovascular tissue engineering. In particular, he focused on vascularized constructs, myocardium, and heart valves. $\mathrm{He}$ also summarized challenges associated with the technology and future directions such as whole organ printing.

All papers published in ABME during 2018 will be considered for awards to be presented at the 2019 BMES Annual Meeting. Awardees will be notified in July, and invited to receive their awards in person during a plenary session at the meeting. We look forward to recognizing the authors of our most impactful papers at BMES in Philadelphia this year.

\section{REFERENCES}

${ }^{1}$ Campolettano, E. T., M. L. Bland, R. A. Gellner, D. W. Sproule, B. Rowson, A. M. Tyson, S. M. Duma, and S. Rowson. Ranges of injury risk associated with impact from unmanned aircraft systems. Ann. Biomed. Eng. 45:27332741, 2017.

${ }^{2}$ Chatzistergos, P. E., R. Naemi, A. Healy, P. Gerth, and N. Chockalingam. Subject specific optimisation of the stiffness of footwear material for maximum plantar pressure reduction. Ann. Biomed. Eng. 45:1929-1940, 2017. 

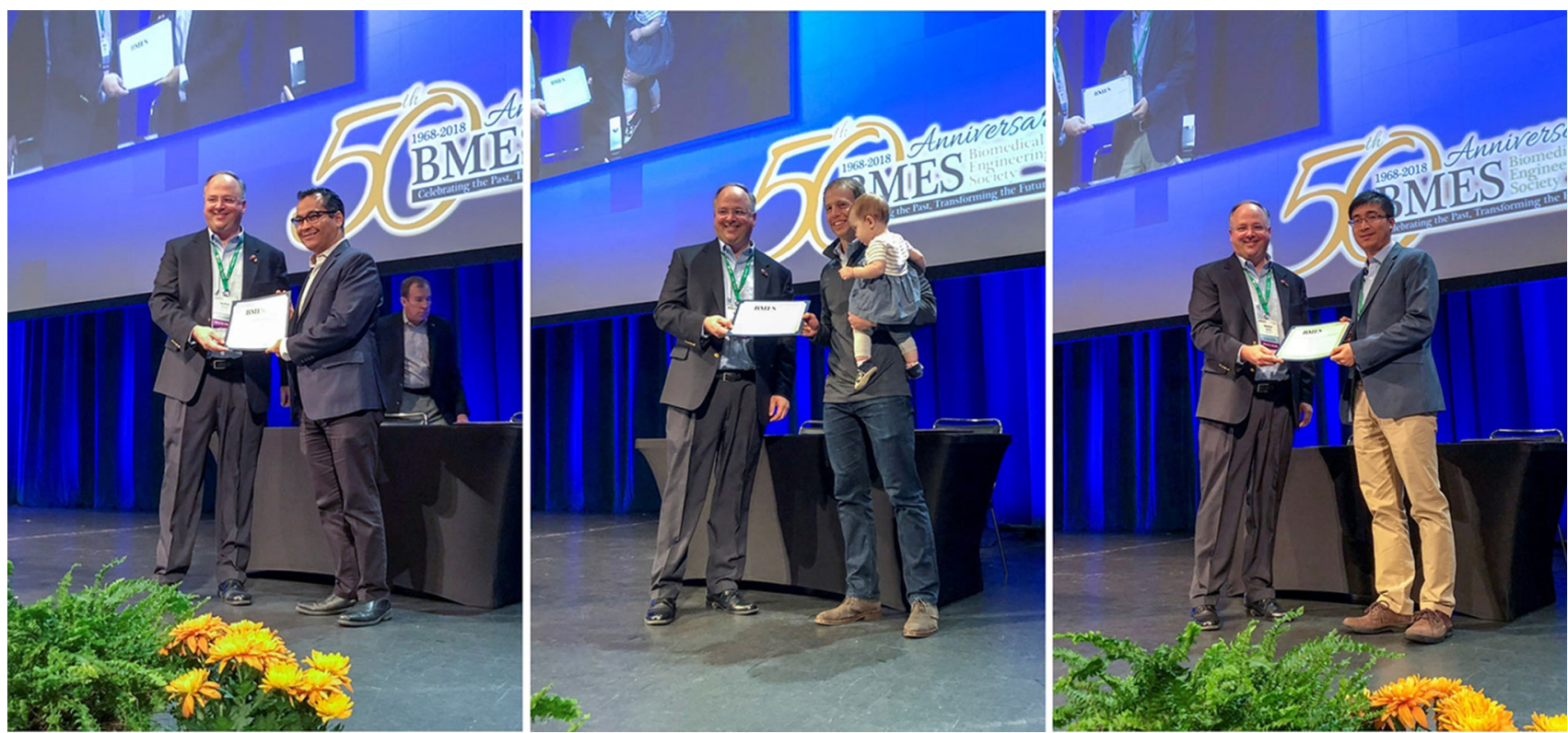

FIGURE 1. ABME awards presented by Editor-in-Chief Stefan Duma at the 2018 BMES Annual Meeting. Pictured left to right: Ali Khademhosseini (most citations), Steven and Juliana Rowson (most downloads), and Bin Duan (editor's choice).

${ }^{3}$ Duan, B. State-of-the-art review of 3D bioprinting for cardiovascular tissue engineering. Ann. Biomed. Eng. 45:195209, 2017.

${ }^{4}$ Müller, M., E. Öztürk, Ø. Arlov, P. Gatenholm, and M. Zenobi-Wong. Alginate sulfate-nanocellulose bioinks for cartilage bioprinting applications. Ann. Biomed. Eng. 45:210-223, 2017

${ }^{5}$ Zadpoor, A. A., and J. Malda. Additive manufacturing of biomaterials, tissues, and organs. Ann. Biomed. Eng. 45:1$11,2017$.

${ }^{6}$ Zhang, Y. S., K. Yue, J. Aleman, K. MollazadehMoghaddam, S. M. Bakht, J. Yang, W. Jia, V. Dell'Erba, P. Assawes, and S. R. Shin. 3D bioprinting for tissue and organ fabrication. Ann. Biomed. Eng. 45:148-163, 2017.

\section{BETHANY RowSON (D}

Department of Biomedical Engineering and Mechanics

Virginia Tech

Electronic mail: browson@vt.edu

Publisher's Note Springer Nature remains neutral with regard to jurisdictional claims in published maps and institutional affiliations. 